\title{
A perspectiva sistêmica na sociologia do direito Luhmann e Teubner
}

Marcelo Pereira de Mello

Introdução

0 objetivo deste artigo é analisar de maneira crítica as contribuições teóricas de N iklas Luhmann e Gunther Teubner para a sociologia do direito. Em termos gerais, este estudo pressupõe a existência de diferenças, mas sobretudo de continuidades entre as teorias desses autores, o que constitui a primeira hipótese do trabalho, ou seja, a de que podemos falar em uma perspectiva sistêmica na sociologia do direito. 0 ponto de partida dessa reflexão será uma revisão dos conceitos fundamentais de ambos os autores: os conceitos elementares da sociologia de Luhmann, a partir dos quais ele desenvolve seu modelo teórico para a análise do direito, e que será, posteriormente, reinterpretado por Teubner na definição de seu direito reflexivo.

A segunda hipótese é de que os conceitos desenvolvidos pela sociologia de Luhmann e por Teubner ocupam um lugar singular na trajetória da sociologia do direito. Luhmann, na medida em que problematiza as teses tradicionais dessa disciplina, aspira, assumidamente, a uma teoria sociológica que supere os impasses da Teoria dos Sistemas de Talcott Parsons, mas quetambém possa suplantar a crítica fenomenológicaà sociologia parsoniana, baseada na afirmação da importância do sujeito na dinâmica da ação social. Em ruptura explícita com os paradigmas sociológicos subjetivistas, Luhmann irá deslocar o foco de sua teoria sistêmica das questões relativas às 
interpretações e aos acordos cognitivos entre os indivíduos para a análisee o desenvolvimento dos códigos sistêmicos em si, e das comunicações possíveis a partir deles.

Teubner, por seu turno, procura incorporar à teoria dos sistemas de Luhmann o conceito de reflexividade, com o qual explica o processo de interação entre fatores externos (pressões sociais) einternos (formalismo jurídico) na configuração dos sistemas jurídicos contemporâneos.

No que se refere à sociologia do direito, Luhmann eTeubner rejeitam frontal mente as abordagens tradicionais, que consideram escapistas diante do problema fundamental da relação entre a sociedadee o direito (cf. Luhmann, 1983, pp. 36-37; Teubner, 1996, pp. 20-22). As evasivas da sociologia do direito manifestam-se, segundo Luhmann, de pelo menos trêsmodos tradicionais: 1) quando as teorias desviam sua atenção do direito para o jurista, por exemplo, numa abordagem na qual o enfoque recai sobre o papel e a profissão do jurista, enão exatamente sobre o objeto e o método do direito; 2) quando tentam deduzir o direito das decisões e do comportamento de pequenos grupos e órgãos colegiados de juízes (tribunais, por exemplo); ou, ainda, 3) quando se restringem simplesmente ao conjunto das opiniões que os diversos grupos e indivíduos têm a respeito do direito. Em todas essas abordagens do fenômeno jurídico, afirma, éo próprio direito que desaparece da sociologia do direito (cf. Luhmann, 1983, pp. 9-12). 0 autor propõe, então, que o fenômeno essencial que caracteriza o direito na sociedadeindustrial moderna, eque, justamente, tem escapado às diversas perspectivas da sociologia do direito, éa positividadedo direito (cf. I dem, p. 34). Por positividadeentende-se aqui o processo legislativo que, no século $X I X$, concebeu de forma inédita que a modificação do direito é parte integrante do próprio direito e imanente a ele. $\mathrm{O}$ u seja, ao contrário da suposição sociológica tradicional de quea positividadeéum constructo da ortodoxiajurídica, equeesta, por sua vez, ésimplesmente o resultado das condições sociais gerais, na realidade a positivação significa que 0 direito passa a ser visto pela legislação como modificável em princípio (cf. Idem, p. 34). $\mathrm{Na}$ formulação de Luhmann, pela primeira vez na $\mathrm{H}$ istória, somente condições legalmente fixadas na legislação podem fundamentar objeções contra a vigência e a validade das leis (cf. I dem, p. 35).

Teubner adota alguns dos princípios do modelo de Luhmann, avança a discussão sobre a autopoi esis do sistema jurídico e assume o desafio de aplicar a teoria sistêmica ao estudo empírico dos fenômenos jurídicos, assim definidos pelo modelo, nas sociedades contemporâneas. Como se demons- 
trará, esse autor realiza um esforço apreciável para dotar a teoria sistêmica desujeitos, ou seja, ele entende que o direito deveser analisado como resultado da interação entre fatores sistêmicos do próprio direito e as pressões políticas pela incorporação de elementos de justiça material. Esse processo é bem descrito na análise que Teubner faz do processo de juridificação das relações sociais nas sociedades contemporâneas.

À guisa de conclusão, oferecemos uma apreciação crítica da Teoria Sistêmica do Direito (TSD), que reintroduz na discussão sobre os fenômenos jurídicos as questões associadas à cognição eà interpretação subjetiva. Veremos como o próprio H umberto M aturana - inspirador de Luhmann e de Teubner no transplante conceitual que fazem da autopoeisis, da biologia para o direito - formula uma importante observação nesse sentido.

A teoria sistêmica de Luhmann: conceitos fundamentais

A concepção sistêmica, segundo a proposta de Luhmann, pretendeexplicar os padrões recursivos das interações entre os atores sociais, os quais formam sistemas de comunicação que, na real idade, constituem a própria natureza das sociedades. 0 autor propõe uma mudança no foco da análise sociológica contemporânea, que para ele está sustentada no que denomina corpus mysticum do sujeito. C ritica, ainda, o fato de todas as perspectivas sociológicas contemporâneas tomarem a ação social como um objeto em si da análise da sociedade. D essa maneira, o autor pretende desconstruir um dos pilares centrais das sociologias contemporâneas: a idéia de que a unidade elementar da análisesociológica são as ações sociais como construção desujeitos, entendidos como atores sociais. Luhmann acena com o seguinte paradoxo para problematizar essa concepção "tradicional": "Pode-se ainda dizer, naturalmente, queossereshumanosagem. M as desdequeisso sempreocorre em situações, a questão que permaneceéseeem que exten são a ação deveser atribuída ao ser humano individual ou à situação" (Luhmann, 1995, p. xliii).

Luhmann acha queasteorias sociológicas contemporâneasfocaram mal o objeto de suas reflexões porque herdaram das teorias racionalistas do século XVIII o conceito deuniversal, ou seja, a preocupação em descobrir os componentes elementares e ao mesmo tempo gerais da vida em sociedade. Essas teorias racional istas, a seu tempo, represaram uma concepção mai santiga do que a própria idéia de sistemas, que era a idéia de conceber os fenômenos como constituídos de um todo e de suas partes. 0 problema dessa tradição racionalista, afirma, équeo todo tinhaqueser entendido num duplo sentido: 
1. Associadasa essesconceitos, as noções de "sistemas abertos" e "sistemasfechados" comple mentam a descrição teóricado modelo. Os"sistemasfechados", afirma, constituem um caso limite: são sistemas para osquaiso ambientenão exerceinfluência ou ela se dá por canais muito específicos (cf. Luhmann, 1995, p. 6). No caso dossistemas sociais, que sua teoria procura explicar, elesconstituem "sistemas abertos". como unidadee como totalidadedesuas partes. A partir disso, podia-sedizer que o todo éatotalidadedesuas partesou, então, queémaisqueumasimples soma de suas partes. Procurar por universais a partir do particular, tentar definir toda a humanidadea partir deum só homem, fez com queos sociólogos fossem buscar nos conceitos de razão, moral social e outros apriorismos, tais como o conceito deeducação ou, ainda, o conceito deEstado, os supostos universais estruturantes dos processos de social ização. Todavia, critica Luhmann, do ponto devista formal isso não explica como o todo, na medida em queé composto de suas partes e de al guma coisa mais, pode ser apresentado como unidade no nível das partes (cf. Idem, p. 5).

Luhmann propõe a superação desse paradigma do todo e da parte por um novo modelo, estruturado a partir da clivagem sistema eambiente ${ }^{1}$. Em vez da dicotomia todo/parte, o autor propõe a idéia de diferenciação sistê mica (system differenciation), quenada mais seria que repetição da diferença sistema/ambiente, dentro do sistema. Um sistema diferenciado, afirma, não é aquele composto por um número extenso de partes e pelas relações entre elas, mas aquele que encerra um número significativo de diferenciações sistema/ambiente em suas operações. C ada uma dessas diferenciações, em cada corte considerado, reproduz a integridade da clivagem sistema/ ambiente (cf. I dem, p. 6). Em resumo, a diferenciação sistêmica nada mais é que a repetição do código do sistema dentro do sistema (cf. I dem, p. 18).

D estarte, o sentido de homogeneidade, que na teoria sociológica tradicional éretirado da noção universal do todo eda parte, ou, em termos sociológicos, das noç̃̃es de indivíduo e sociedade, deve ser substituído, segundo a proposta do autor, por um sentido de homogeneidade retirado da reprodução da clivagem sistema/ambiente ao longo do processo de diferenciação subsistêmica (cf. Idem, p. 7).

$\mathrm{N}$ a teoria desenvolvida por Luhmann, a existência de sistemas é assumida como factual e, além disso, como auto-referencial. Como afirma o autor, o conceito de sistema refere-se a al guma coisa que é em realidade um sistema eque, nesse sentido, assume a responsabilidade de explicar a realidadee testar suas afirmações (cf. Idem, pp. 12-14). Ele destaca que alguns sistemas possuem a capacidade de estabelecer relações internas com seus próprios elementos constitutivos e de diferenciá-las das relações que mantêm com 0 ambiente. $\mathrm{N}$ o limite, entretanto, não há sistema sem ambiente nem ambientes estruturados que não possam ser percebidos por sua organização sistêmica. 0 s sistemas estão orientados pelos seus ambientes não apenas de maneira ocasional e por adaptação, mas também estruturalmente - não 
podem, na realidade, existir sem um ambiente. Eles se constituem e se conservam como tais ao criar e manter a diferença de seus ambientes, eseus limites com o ambiente servem para regular essa diferença. Sem a diferença com o ambiente não haveria a auto-referência, porque ela éa premissa funcional das operações auto-referenciadas (cf. Idem, p. 14).

Em termos genéricos, essa concepção de sistemas auto-referenciados será utilizada posteriormente por Luhmann e por Teubner para explicar o "siste ma legal". Segundo Luhmann (1986, p. 112), partindo-se da estrutura geral da teoria da sociedade como um sistema social funcionalmente dife renciado, o sistema legal deve ser entendido como um de seus subsistemas funcionais. Tal sistema, afirma, constitui a si próprio a partir de suas funções, determinadas no nível do sistema societário. 0 s arranjos função/sistema requerem total autonomia funcional porque nenhum outro sistema de sempenhará as mesmas funções que aquele. N esse sentido, a autonomia não é um objetivo perseguido pelo sistema, mas uma necessidade fática (cf. I dem, p. 112). No caso específico do sistema legal, todas as suas unidades elementares, os atos legais, bem como a unidade do sistema como um todo, são ativadas a partir do que o autor chama de redução de complexidades. A partir desse processo, os sistemas submetem os estímulos do ambiente a seus padrões próprios de entendimento e processamento sistêmico.

Luhmann absorve, nessa passagem, o conceito de autopoiesis desenvolvido por M aturana eVarela (1980), para afirmar que os subsistemas funcionais da sociedade são sempre auto-referenciais, ou seja, produzem e reproduzem a si próprios. Eles constituem seus componentes pelo arranjo próprio desses componentes, o que constitui propriamente sua unidade e, portanto, seu fechamento autopoiético. A extensão do conceito de auto-referência do nível agregado da estrutura para o nível dos elementos do sistema constitui, segundo Luhmann, a mais importante contribuição da teoria de $M$ aturana e Varela para 0 entendimento de todo esse processo (cf. Luhmann, 1995).

$\mathrm{N}$ o entanto, a idéia de que o sistema legal constitui um sistema fechado não deve obscurecer o fato de que todo sistema mantém conexões com seu ambiente. Luhmann formula essa concepção da seguinte maneira: 0 sistema legal éaberto porqueéfechado e éfechado porqueéaberto. $N$ ão se trata deum simples jogo de palavras. 0 autor, com esse paradoxo, quer expressar a forma particular do relacionamento entre o sistema legal e 0 ambiente societário. Como afirma, o sistema legal tem seu componente e sua forma própria de expressão: a norma; e seu modo próprio de operação, o código 
lícito e ilícito. Pode haver influência política na legislação, mas somente a lei pode modificar a lei. Somente dentro do sistema legal a mudança das normas legais pode ser percebida como mudança da lei (cf. Luhmann, 1986, p. 113). Ao que acrescenta: é sempre uma norma que decide quais fatos têm relevância legal ou não. $N$ esse sentido, o sistema legal é um sistema normativamentefechado.

Ao mesmo tempo, o sistema jurídico é "cognitivamente aberto", o quer dizer que é estimulado pelas informações do ambiente. No caso específico do sistema legal, ele retira parte de sua dinâmica própria do processamento que realiza, segundo seu código, dos estímulos dos demais subsistemas sociais: político, econômico, educacional, moral etc. $\mathrm{N}$ a verdade, a friç̧ão entre os subsistemas auto-referenciados e $o$ ambiente é o que produz informação. I sso não seria possível, no entanto, se o sistema legal fosse apenas um sistema denormas eo ambiente fosse apenas cognição. Luhmann (1986, p. 114) enfatiza, então, que o sistema legal não é um sistema normativo no sentido de seus componentes serem os conteúdos das normas, ou no sentido ainda de "determinarem" o funcionamento do ambiente, mas sim um sistema de operações legais que usa sua auto-referência normativa para reproduzir asi próprio epara selecionar informações do meio. 0 autor chama de dupla contingência dos sistemas o fato de eles operarem de maneira normativamente fechada, o que requer relações simétricas entre seus componentes, na medida em que um elemento dá sustentação ao outro e viceversa, e, ao mesmo tempo, operarem de maneira cognitivamente aberta, na qual a assimetria entre o sistema e seu ambiente os força a uma recíproca adaptação e mudança. 0 s sistemas legais, afirma, apresentam uma maneira especial de resolver esse problema ao combinar disposições normativas e cognitivas, eestabelecer condicionalidades para a introdução no sistema dos estímulos do ambiente. $\mathrm{N}$ esse sentido, as normas legais, diferentemente das concepções de K elsen e D urkheim, não derivam de uma ordem legal factual nem de uma norma fundamental, mas são "programas de condicionalidades" para a introdução no sistema dos estímulos [informações] do ambiente (cf. Idem, pp. 115-119). 0 sistema legal, enfatiza o autor, não determina o conteúdo das decisões legais, nem logicamente nem por intermédio de procedimentos técnicos de uma hermenêutica jurídica. Ele opera como um sistema ao mesmo tempo "fechado normativamente", o que garante sua manutenção e auto-reprodução, e "aberto cognitivamente", no sentido de que está em contínua adaptação às exigências do ambiente. 
Relativizando o sistema: Teubner e o conceito de historicidade e reflexividade do direito

0 modelo analítico de Gunther Teubner para o entendimento do sistema jurídico caminha em dois sentidos aparentemente contrários: de um lado, o autor procura aprofundar a apropriação do modelo biológico da autopoies s proposto por M aturana e Varela (1980) para explicar o sistema jurídico; de outro, procura incorporar variáveis historicistas (sociais e políticas) na explicação do fenômeno jurídico, especialmente no contexto do que chama de processo de "juridificação". 0 enfrentamento dessa dupla problemática ocorre na obra deTeubner, creio, porque el eaceitou o desafio de confrontar os princípios da teoria sistêmica, desenvolvida com base nos trabalhos de Luhmann, com a realidade concreta dos sistemas jurídicos europeus, desenvolvidos no contexto do chamado WelfareState. Ao fim eao cabo, o conceito de direito reflexivo surge como a contribuição mais significativa do autor à teoria sistêmica porque, como veremos, procura estabele cer as condições da comunicação sistema/ambiente, no caso concreto da interação entre sistema jurídico esubsistemas social, político e econômico.

0 enfrentamento desse Jano bifronte, corporificado no duplo esforço para extrair todas as conseqüências da auto-referencial idade do sistema jurídico e, portanto, o aprofundamento da aplicação da noção de autopoiesisà compreensão do sistema jurídico, juntamente com a tentativa de explicação dos processos históricos dos sistemas legais de países europeus que desenvolveram o WelfareState, não éfeito, contudo, sem que o autor incorra em al gumas revisões à teoria sistêmica de Luhmann.

Teubner começa por redimensionar o próprio conceito de autopoi esis, desenvolvido por M aturana e Varela, e a própria definição dada por Luhmann, ao afirmar que esses autores trabalham com um conceito de autopoi esiscaracterizado por uma "rigidez inflexível", como um processo detudo ou nada: o direito ou reproduz ou não reproduz a si próprio, não existindo algo como uma gradação no fenômeno da autopoi esis. "A meu ver, autonomia e autopoiesis deveriam antes ser entendidos como conceitos gradativos" (Teubner, 1989, p. 57).

Segundo Teubner, a auto-referência e a autopoi esis constituem critérios precisos para a caracterização dos sucessivos graus ou etapas de autonomia. U tilizando-se da definição de autopoiesis de $G$ erhart R oth (1987)², o autor afirma que um sistema se torna crescentemente auto-referencial quando a 2. Citado em Teubner (1989).

redede seus componentes sofre modificações do seguintetipo: maior feedback 
entre seus componentes, plasticidade funcional e plasticidade estrutural, e constituição de novos componentes dentro da rede de componentes (cf. Teubner, 1989, p. 67). U m sistema jurídico torna-se autônomo, afirma, na medida em que consegue constituir seus elementos - ações, normas, processos, identidade- em ciclos auto-referenciais, só atingindo o termo pertinente de sua autonomia autopoi ética quando os componentes do sistema, assim ciclicamente constituídos, searticulam, por sua vez, entresi, formando um "hiperciclo" (cf. I dem, pp. 58-67).

$\mathrm{N}$ esse sentido, a auto-referência e a autopoiesis vêm dar origem a um novo emais elaborado tipo deautonomia do sistema jurídico em virtudeda constituição de relações circulares, autonomia que, de modo al gum, exclui a existência de interdependências causais entre o sistema jurídico e o sistema social (cf. I dem, p. 56). Essa espécie de autopoi esis mitigada é pensada por Teubner a partir da distinção entre três elementos embutidos no processo de aumento cumulativo de relações circulares - o "hiperciclo" - eque fazem da autopoi esis um processo gradativo: a auto-observação, a autoconstituição e a auto-reprodução. Segundo o autor:

U macoisaéum subsistema social observar os seus componentes (elementos, estruturas, processos, limites, identidade e meio envolvente) através de comunicação reflexiva (auto-observação); outra diferenteéum sistema definir ecolocar em operação por si só o conjunto dos componentes sistêmi cos (autoconstitui ição); ainda uma outra coisa dife renteéa capacidade de um sistema para se reproduzir asi mesmo através da produção (circular erecursiva) denovos elementosa partir deseus próprios elementos(autopoie sis) (Idem, p. 68).

D euma maneira geral, afirma o autor, o grau deautonomia dos subsistemas sociaisédeterminado por uma escala crescenteque parteda satisfação da primeira linha de exigências, ou seja, da definição auto-referencial de seus componentes, passa pela incorporação eutilização operativa do sistema dessa auto-observação e, final mente, pela articulação hi perć́clica dos componentes sistêmicos autoconstituídos. Para evitar qual quer confusão com al guma teleologia, Teubner se apressa em dizer que esses complexos hiperciclos que constituem osprocessos deautopoi esisdos subsistemas sociaisnão evoluem de acordo com padrões predeterminados ou em direção à consecução deum fim particular: "As suto-observações surgem, por assim dizer, espontaneamente. Semprequeumadistinção éaplicada a fenômenossociais, mais cedo ou mais tarde acaba também por ser aplicada a si mesma" (I dem, p. 68). 
N esse sentido, a chave para a compreensão da autonomia do sistema jurídico reside, segundo o autor, nessa relação tripartite de auto-observação, autoconstituição eauto-reprodução. Logo que a comunicação jurídica sobre a distinção básica lícito/ilícito comece a diferenciar-se da comunicação social geral, ela se torna inevitavelmente auto-referencial eé compelida a tematizar a si mesma, tendo por referência as categorias intrinsecamente jurídicas. D euma maneira geral, esseé o processo que conduz à emergência de "círculos auto-referenciais" no que respeita a atos jurídicos, normas jurídicas, processos jurídicos e dogmática jurídica, o que, por sua vez, implica uma mai or autonomia do sistema jurídico. 0 sistemajurídico torna-se perfeitamente auto-reprodutivo, afirma, apenas quando seus componentes sistêmicos auto-referencialmente constituídos se encontram de tal modo imbricados que atos e normas jurídicas se produzem reciprocamente entre si, e o processo jurídico e a doutrina jurídica relacionam por seu turno essas inter-relações (cf. I dem, p. 71). Em sentido estrito, portanto, a autonomia jurídica abrange não apenas a capacidade do direito de criar seus próprios princípios, mas também de autoconstituição de ações, a juridificação dos processos e a criação de institutos "jurídico-doutrinais" (cf. Idem, p. 72).

Essa concepção de autonomia do direito difere de outras formuladas por três tradi ções da reflexão sociológica sobre o sistema jurídico. Por um lado, ela se diferencia da reflexão marxista sobre a relação base-superestrutura na determinação do fenômeno jurídico pelos sistemas socioeconômicos, em que a "relativa" autonomia do si stema jurídico estaria ainda assim determinada pelos interesses materiais em disputa pelas classes sociais. Por outro, também se particulariza das teses sociológicas mais tradicionais, que afirmam queo sistema jurídico, mesmo quando independente dos demais poderes constituídos, como nas democracias ocidentais, não são autônomos em relação ao conjunto das demandas socialmente constituídas. E, por fim, repele a explicação das teorias que procuram relacionar a autonomia do direito com um processo corporativista construído por advogados, juízes e especialistas, como na tradição de Watson ${ }^{3}$.

C ontra os primeiros, os marxistas, etambém contra as teorias sociológicas que de modo geral postulam a existência de nexos causais mecânicos entre os sistemas jurídico e social, Teubner argumenta que muito tempo foi perdido com o falso problema de se a constituição de um sistema jurídico autopoi ético induz à criação de uma espécie de "autarquia do direito" ou se, ao contrário, o direito é dependente dos sistemas econômico e político, ou seja, não há uma independência causal entre esses elementos. Se-
3. A referência aqui éa Alan Watson, autor que desenvolveu a tese dos transplantes legais. Ver Watson (1974). 
4. 0 termo "transplante legal (ou jurídico)" é uma idéia subjacenteà perspectiva de autonomiado sistemajurídico, daqual Alan Watson éo representanteprincipal. gundo Teubner, a autonomia jurídica reside no caráter circular da produção do direito, e não numa mera independência causal relativa ao meio envolvente. Isso, com efeito, não significa negar a existência de nexos causais entre os sistemas jurídicos e os demais subsistemas sociais. Apenas, afirma, em face da característica de circularidade da organização interna do sistema jurídico, os modelos de causalidade explicativos das influências externas respectivas tornam-se necessariamente mais complexos. Em vez de uma simples lógica causa-efeito, deve-se utilizar o que Teubner chama de lógica de "perturbação" (cf. I dem, p. 74). N esse sentido, afirma, os fatores capazes de influenciar do exterior o direito devem ser descritos como um problema de influência externa sobre processos causais circulares internos (cf. Idem, p. 74).

ContraAlan Watson, que procura explicar a "autonomia" do direito como um processo gradativo deconstrução de um sistema legal baseado em normas jurídicas como representações dos valores sociais subjacentes, mas quesevão libertando simultaneamente desses mesmos valores, autonomizando-se a ponto de se poder "transplantar"4 ordens jurídicas similares em contextos sociais completamente diversos, Teubner afirma quea verdadeira razão para isso deveser buscada no fenômeno da circularidade. Watson procura explicar esse processo invocando como sujeitos dessa aparentevida própria do direito as elites profissionais jurídicas e a disseminação de uma cultura e de uma consciência dos juristas, o queTeubner afirma ser de somenos importância para o entendimento da autonomia do direito.

Em contraposição a esse tipo de hipótese, o autor afirma que os standards jurídicos, antes de representarem algum efeito de autonomização do direito em relação aos processos sociais, representam um fenômeno estrutural de auto-referência do direito. $\mathrm{O}$ u, como afirma, esse fenômeno deve ser entendido em termos da relação entre auto-referência e formalidade: "se as normas são auto-referencialmente constituídas [...] elas tornam-se 'formais's no sentido deque (hetero-)referências para o meio social envolvente são eliminadas em favor de (auto-)referências para si mesmas" (Idem, pp. 83-84).

0 modelo explicativo de Teubner é bastante enrobustecido com o desenvolvimento do conceito de reflexividade (reflexivité) ou, mais especificamente, direito reflexivo (cf. Teubner, 1996). N ovamente, a preocupação do autor édotar a teoria sistêmica e o conceito deautopoiesisde poder explicativo das configurações institucionais concretas ("empíricas") do sistema jurídico. No caso específico, ele polemiza com as explicações correntes do fenô- 
meno da "materialização" do direito eseus efeitos no processo de juridificação das relações sociais no contexto do Welfare State. Ele renega especialmentea explicação, que atribui a Weber, de que o processo de materialização do direito estaria em descompasso, ou seja, seria um processo marginal à tendência histórica de racional ização e formalização das relações jurídicas ${ }^{5}$ da civilização ocidental.

A idéia deTeubner é produzir uma explicação para o fenômeno jurídico que esteja situada a um meio-termo entre as teorias sociológicas em sua opinião excessivamente sociocentradas, como as de Weber eas teorias marxistas inspiradas na distinção entre estrutura e superestrutura, e a teoria de N onet e Selznick (2001 [1978]), especialmente o conceito de direito responsivo, com o qual os autores procuram explicar o mesmo processo, ou seja, as tendências antiformais do direito contemporâneo, só quea partir da crise interna do formalismo jurídico (cf. Teubner, 1996, p. 5). Essa clivagem entre elementos internos e externos ao direito, Teubner a estende, ainda, às teorias dos próprios $\mathrm{N}$ onet e Selznick e às de Luhmann e $\mathrm{H}$ abermas. Enquanto os primeiros trabal ham com variáveis internas ao sistema jurídico para explicar o fenômeno da materialização do direito, tais como estrutura conceitual e doutrinária, métodos de instrução, de procedimentos institucionais e model os de partici pação, Luhmann e H abermas apóiam-se explicitamente em variáveis sociais externas. Luhmann, segundo essa interpretação, atribui as tendências de crise do direito formal a problemas de adaptação à diferenciação funcional da sociedade e aponta como solução uma maior autonomia do direito, uma abstração mais pronunciada dos conceitos jurídicos, maior auto-reflexão do sistema e um novo funcionalismo da doutrina. $\mathrm{H}$ abermas, ao contrário, considera quea racionalidade formal do direito está ligada a uma crise geral de legitimidade do capitalismo organizado. Para vencer essa crise, deve-seinstitucional izar uma nova razão comunicacional da normatividade, para transformar as estruturas jurídicas da sociedade em geral (cf. Teubner, 1989).

Teubner propõe, então, queesses modelos, que são complementares- na medida em que N onet e Selznick ${ }^{6}$ trabalham com variáveis "internas", ao passo que Luhmann eH abermas operam com variáveis sociais "externas" -, ensejam o desenvolvimento de um novo tipo jurídico, "reflexivo", capaz de sopesar e confrontar os limites internos da racionalidade formal do direito com as exigências estruturais e funcionais das sociedades pós-modernas. Embora bastante influenciado pelas idéias de $\mathrm{N}$ onet eSelznick a respeito do direito responsivo, Teubner afirma que uma limitação importante dessecon-
5. M ais adianteiremos discutir em particular essa que considero ser umainterpretação equivocadamente evolucionistaemecanicistadasociologia do direito de M axWeber, pelasrazões em parte expostas na nossainterpretação dessateoria.

6. Gunther Teubner (1996) apóia-se amplamente nas idéias de PhilippeN onet ePhilip Selznick desenvolvidas em seu livro de 2001, Law and Society in Transition. 
ceito é que ele não é capaz de distinguir sistematicamente racionalidade material eracionalidade reflexiva. Em seu lugar, o autor opta por um modelo quesupõetrêstipos dedireito (formal, material e reflexivo) dimensionados por três níveis distintos (racionalidade interna, racionalidade normativa, racionalidade sistêmica). D ito simplificadamente, o modelo proposto por Teubner operaria deforma a identificar em cada momento concreto da evolução da sociedade uma configuração particular desses três tipos de direito. Segundo ele, o processo jurídico de reflexão define a autolimitação do direito, mas sempre dentro do contexto de seus vínculos com a realidade social. Segundo a perspectiva da reflexividade do direito, o sistema jurídico considera a si próprio como um sistema dentro de um ambiente, e reconhece os limites de sua capacidade de regulação dos outros sistemas sociais.

Continuidades e rupturas entre a teoria sistêmica e as sociologias do direito tradicionais

Está claro que aTeoria Sistêmica do D ireito (TSD ), subsumida em nosso trabal ho nas teorias de Luhmann eTeubner, muda sensivelmente o foco das teorias sociológicas tradicionais sobreo direito, ancoradas nas teses fundamentais das teorias de M arx, Weber, D urkheim, e em uma enorme gama de teorias nelas inspiradas. A TSD problematiza especialmente a hipótese sociológica tradicional sobre a suposta determinação social, política e econômica (as ênfases variam) dos conteúdos do direito. Luhmann argumenta que "a sociologia do direito está interessada somente nas conexões entre variáveis legais e extral egais e, embora todas elas falem de unidade do sistema legal, esta unidade nunca é claramente percebida" (Luhmann, 1988, p. 13). Com bastante propriedade, Teubner $(1996$, p. 8) chama de positivistas todas essas teorias (inclusive as marxistas) que reduzem o direito ao simples reflexo das relações de poder, esuas respectivas estruturas sociais eeconômicas de base.

Um dos elementos fundamentais para entendermos a mudança do enfoque das teorias sistêmicas do direito em relação às teorias sociológicas tradicionais está na compreensão da distinção entre independência, autonomia e autopoiesis do sistema jurídico.

LawrenceFriedman (1986, p. 14), um dos mais expressivos representantes daescola sociológica do direito, argumenta, por exemplo, queum dosproblemas clássicos da sociologia do direito gravita em torno da questão da autonomia (ou da falta dela) do sistema jurídico. Sua posição a esse respeito é de 
que se deve buscar uma explicação intermediária entreas interpretações que atribuem àsforças sociaisum poder depressão irresistível ao sistema legal e, na posição oposta, as teoriassistêmicas que assumem queo sistema legal éautônomo, no sentido deque possui um conteúdo e uma lógica próprios einde pendentes de influências externas. Contra a idéia de autonomia do sistema jurídico, Friedman argumenta que a perspectiva de "insulamento" contra 0 mundo externo podetrazer, em termos práticos, uma sériedeinconveniências, como conservadorismo e resistências cegas a qual quer tipo de mudanças demandadas por grupos sociais, seusinteresses legítimose seusval ores. Ainda que, em contrapartida, em seu aspecto positivo, o "insulamento" do sistema legal possa oferecer maiores garantias com respeito aos direitoshumanos, das minoriase dos cidadãos contra o Estado. Friedman afirma queem vez deautonomiaémaisadequado falar em "independência" do sistemalegal, no sentido de queal guns segmentos desse sistema, por exemplo o poder judiciário, têm independência deação quanto a guardarem relativa autonomia com respeito àspressões externas. M asnão sedevetomar "independência" por "autonomia" do sistema. 0 autor reforça, então, um dosargumentossociológicosclássicos, o dequeas sociedades, especialmenteas democráticas ocidentais, são abertas a influências desetores do governo, da pressão deeleitores, da opinião pública, dos grupos de interesseetc. (cf. I dem, p. 17). Sua tese principal éa deque o conceito de "cultura legal", ou seja, o conjunto das idéias, das atitudesedas crenças compartilhadas pelas pessoas acerca do sistema legal, éo maisadequa do paraacompreensão do incontornável processo demediação entre o sistema legal ea organização social. E exemplifica: embora dois homens ou duasmuIheres dificilmente possuam as mesmas atitudes e compreensão da lei e do direito, pode-se, com segurança, retirar tendências e correlações sistêmicas dessas atitudes deacordo com idade, sexo, renda, nacionalidadeetc. Por fim, destaca que o concei to de autonomia do sistemajurídico no sentido da autopoi esisem nada se diferencia daquilo queW eber definiu como racionalidade formal, uma das características inequívocas do direito ocidental contemporât neo (cf. Idem, pp. 16-17).

Em outra versão da crítica sociológica àTeoriaSistêmica do D ireito (TSD ), Richard Lempert (1988) confronta a idéa de autopoi esis com seu conceito de autonomia legal. Segundo o autor, autopoiesis e autonomia legal delimitam duas visões sobre o fenômeno da "autonomia" dos sistemas legais, que remetem às tradições anglo-americana e européia ocidental. A primeira, a visão "anglo-americana", é fortemente influenciada por estudos empíricos sobre a maneira como o poder das leis se articula com outras fontes de 
7.Em Luhmann, mas sobretudo em Teubner, háuma compreen são de quea autopoi esis do direito se realiza em diferentes níveis ou gradações. poder na sociedade. A segunda, afirma o autor, reflete o fato de que a perspectiva de autonomia do sistema legal na visão "continental" parte de uma "abstração" (o sistema legal como um subsi stema dos sistemas sociais) "de uma abstração" (os sistemas sociais como análogos aos si stemas biológicos). I sso conduz à segunda diferença entre essas perspectivas, delimitada por Lempert, queéo fato de a sociologia do direito na tradição anglo-americana estar mais focada na análise de casos concretose particulares de autonomias legais, conduzidos com rigor estatístico.

$\mathrm{N}$ a medida em que as sociedades estão organizadas em padrões socioeconômicos, a influência desses padrões na produção de nichos de autonomia no sistema legal pode ser reunida, segundo o pressuposto do autor, em séries estatísticas que permitem comparações e dispensam teleologias. $\mathrm{N}$ a versão "continental" - em nossos termos, sistêmica - , Lempert afirma quea concepção deautopoi esispressupõe reconstituição cíclica constante, deacordo com as modificações do ambiente. I sso conduz a uma concepção "evolucionista" do sistema legal, mascarada pelo que os autores dessa corrente sistêmica chamam de adaptação.

Lempert critica ainda a versão renovada do funcionalismo sociológico embutida na concepção de autopoi eśs, na medida em que o próprio Luhmann assegura que o sistema legal preenche uma função especial e única nas soci edades diferenciadas, ao mesmo tempo em que realização da autopoi esis do direito em seu mais alto nível de autonomia ${ }^{7}$ apenas se daria em sociedades bastante diferenciadas do ponto de vista da especialização funcional de seus subsistemas. Finalmente, Lempert critica a idéia de Luhmann de que o sistema legal é cognitivamente aberto e normativamente fechado, afirmando que essa é uma formulação muito genérica e que não responde a questão fundamental para a sociologia do direito, a saber, as maneiras pelas quais mudanças normativas no sistema legal estão associadas às pressões sociais (cf. Lempert, 1988, p. 188).

Por todas essas razões, em vez de autopoiesis, Lempert prefere trabalhar com o que chama de autonomia relativa do sistema legal, em que a autonomia do direito é relativa ao grau de importância dos padrões internos de ação e de procedimento para a criação e a aplicação da lei vis-à-vis os padrões externos ao sistema jurídico de natureza política ou social. E conclui: a autonomia do D ireito é mais bem ilustrada na aplicação da lei e no processo judicial do que na criação da lei e no processo legislativo. 


\section{Continuidades}

As críticas formuladas por Lawrence Friedman e Richard Lempert àteoria sistêmica são interessantes porque canalizam e expressam as idéias e as teses fundamentais da sociologia do direito mais fortemente ofendidas com as inovações teóricas dos trabal hos de N iklas Luhmann e Gunther Teubner. Ambos, curiosamente, Friedman e Lempert, reagem, por caminhos diferentes, da mesma forma à teoria sistêmica, quando a acusam de ser muito ambígua, incapaz de ser testada empiricamente e, na verdade, só estar afirmando o que já se sabe sobre o sistema jurídico, porém utilizando uma linguagem desnecessariamente complicada.

D e al gumas críticas é difícil discordar. Por exemplo, a afirmação de que a teoria de Luhmann incorpora vários dos pressupostos da teoria sistêmica deTalcott Parsons e que, portanto, fica sujeita ao arsenal de críticas já realizadas ao modelo parsoniano (cf. N elken, 1988). As noções de sistema e subsistemas, especialização funcional, cibernética, redução de complexidades (Parsons chama isso de "pautas de desenvolvimento da ação") em tudo se parecem aos conceitos parsonianos para explicar o sistema ea ação social. Com a ressalva de que Luhmann foi ainda mais radical do que o próprio Parsons na sua concepção de sistema, uma vez que, para ele, a unidade básica da análise sociológica, ou a unidade básica do sistema, são as comunicações e não as ações individuais pautadas pelos subsistemas, como na versão de Parsons. N esse aspecto, Luhmann distancia-seainda da sociologia compreensiva de $\mathrm{M}$ ax Weber edas perspectivas fenomenológicas de maneira geral, que concebem a ação social como resultado do significado intersubjetivo atribuído interpretativamente pelos sujeitos da ação. Em Luhmann, a concep ção de que os padrões recorrentes da ordem são dados pelos códigos da comunicação sistêmica é o que permite a incorporação à teoria desse autor do conceito biológico de autopoiesis utilizado para explicar os sistemas sociais e, posteriormente, o "subsistema legal".

U m segundo tipo de crítica à TSD, condensada nos trabal hos de Friedman e Lempert, diz respeito ao caráter evolucionista de suas proposições. Essa crítica, parece-me, se aplica melhor a Teubner, pelas razões que descrevemos na breve introdução de sua teoria e que se relacionam com as noções dereflexividadee historicidade. C omo vimos, esse autor assume como desafio a aplicação da noção de direito autopoi ético em contextos reai se concretos, à maneira dosempiristas, eem seu trabal ho D roit et reflexivité(1996) toma da seguinteforma o tema da juridificação edo WelfareState para a apli- 
cação dos princípios da análise autopoi ética: ele parteda interpretação da sociologia do direito deM axW eber, imputando-Iheum diagnóstico segundo 0 qual, para Weber, o direito contemporâneo (início do século XX) estaria eXperimentando um desenvolvimento marcado pelatensão entreduastendências contraditórias: de um lado, o sistema jurídico reforça sua especial ização "formal", seu profissionalismo esua sistematização interna, e, deoutro, revivifica uma tendência de materialização caracterizada pela internalização de elementos éticos e morais e de postulados democráticos aos processos judiciais. Teubner, por seu turno, localiza nos sistemas enas "redes" de proteção social construídos ao abrigo das políticas públicas de bem-estar social (welfare) - que, segundo o autor, estariam redefinindo os contornos institucionais do direito, bem como os conteúdos e os significados da lei - um exemplo empírico datensão entreformalismo ematerialização, característica do processo de judi cialização analisado por vários autores. D esse ponto de vista, o processo de judicialização não éintrinsecamentebom ou ruim, mas incontornável porque relacionado ao fenômeno da crescente especial ização funcional das sociedades esua repercussão no sistemajurídico.

D o nosso ponto de vista, esse tipo de proposição respalda as críticas a respeito do evolucionismo da teoria sistêmica na medida em que esta postula um processo "progressivo", "graduado", em diversos "níveis de profundidade" do fenômeno da autopoi esis, al cançados segundo o correspondente avanço progressivo e integrado ("aberto" e "fechado") do sistema jurídico com os demais subsistemas sociais. Por detrás da concepção da capacidade plena de auto-reprodução dos subsistemas sociais a partir do fenômeno da autopoi esis, há uma indisfarçável idéia de classificação das sociedades em complexas e simples a partir da profundidade e da extensão da especialização funcional observada em cada uma delas. Teubner acolhea concepção de Luhmann de que as estruturas normativas (por exemplo, o direito e a moral) funcionam como mecanismos de variação, ao passo que a seleção e a estabilização do sistema são reforçadas simultaneamente pelas instituições de procedimento e pela abstração conceitual. A interação desses elementos produz certas configurações de evolução: direito arcaico, alta cultura jurídica e direito positivo (cf. Teubner, 1996, p. 10). Teubner ressalva a crítica de evolucionismo da teoria sistêmica ao dizer queo próprio Luhmann recusava algumas hipóteses centrais do evolucionismo clássico, como a linearidade, a necessidade e o progresso. M as ele próprio não escapa de chamar de "versão minimalista da teoria da evolução" as hipóteses da perspectiva sistêmica (cf. Idem, p. 72). 
0 evolucionismo historicista de Teubner fica caracterizado ainda pela leitura que ele faz dos escritos de $M$ ax Weber sobre 0 direito. 0 ponto de partida correto dessa interpretação, na nossa opinião, é quando o autor atribui a W eber a caracterização de duas ten dências contrárias de desenvolvimento do direito: por um lado, um processo progressivo de especialização formal, administrado de forma profissional e com incremento da sistematização interna; por outro, um processo em que o direito éexposto às exigências igualmente progressivas que o fazem incorporar elementos de justiça material, como conceitos de democratização e justiça social (cf. Teubner, 1989, p. 71). Entretanto, diferentemente do queTeubner diz (cf. I dem, p. 72), Weber não apresenta essa questão como um "paradoxo" no processo "evolutivo" do direito. Q uando afirmava que o direito comercial europeu ocidental está eivado de princípios de justiça material, como confiança, credibilidade etc., Weber não estava dizendo que haveria uma tendência progressiva de formalização e racionalização do direito comercial, mas ape nas reconhecendo a natureza da sua constituição, resultado da combinação de formalização e princípios de justiça material fixados pelos costumes dos negócios comerciais. $\mathrm{N}$ ada mais. Enfim, para Weber, a racionalização do 0 cidente expressa no direito indicava um sentido, não um fim.

\section{Rupturas}

As críticas mais acerbas à teoria sistêmica não devem obscurecer, entre tanto, as contribuições mais significativas desse modelo para a compreen são dos nexos entre o sistema jurídico eas relações sociais. Em primeiro lugar, a teoria sistêmica acrescenta, no mínimo, um aspecto novo à sociologia do direito, quando analisa a forma como o sistema jurídico cria realidades descortinadas pelo código lícito e ilícito com efeitos sensíveis nas comunicações dos indivíduos, ou seja, nas relações sociais. 0 direito, nessa perspectiva, não representa um "indicador externo" das moralidades sociais, como na expressão de D urkheim, ou um documento autenticado das relações de dominação entre as classes sociais, ou, ainda, um reflexo dos interesses estratégicos de grupos de qual quer natureza. Sem desconhecer esses aspectos, todos influentes no direito, ou qualquer outro estímulo do ambiente moral, político, artístico e científico da criação dos sistemas jurídicos, a teoria sistêmica problematiza a relação entre direito e sociedade a partir do direito. E isso significa contemplar a forma como o código binário essencial do sistema jurídico (lícito/ilícito) não apenas determina a recepção dos estí- 
mulos do meio, mas, ao mesmo tempo, condiciona a expressão da comunicação e de seus conteúdos entre os agentes sociais.

Segundo Teubner, pode-se reconstruir os "modelos" da realidade social sobre os quais se apóiam as normas jurídicas, as decisões judiciais e as considerações doutrinais do direito. D o ponto de vista da instrução das decisões jurídicas, prossegue, esses modelos servem de pano de fundo cognitivo, uma espécie de pré compreensão do problema. 0 smodelos de contrato, de associação, de empreendimento etc. são, nesse sentido, construções especificamente jurídicas que se distanciam das formulações do senso comum, mas igualmente das formulações teóricas ecientíficas. Essa diferença reflete a condição essencial da resolução jurídica dos conflitos sociais: para isso, do ponto de vista normativo, o sistema jurídico deve constituir-se como uma realidade própria, um enclave de realidade entre realidades, no sentido fenomenológico. $D$ a perspectiva da solução jurídica dos conflitos, o direito se crê um mundo à parte entre outros mundos igualmente seletivos da realidade e, por essa razão, o sistema jurídico negligencia inúmeros elementos que são percebidos como pertinentes e até mesmo relevantes para as esferas da vida política, social ou econômica (cf. Idem, p. 48).

0 mesmo diz Luhmann a respeito da auto-reprodução do direito quando afirma que as pessoas, para serem clientes do sistema legal, precisam operar dentro dele, o que vale dizer que precisam conceber o problema de uma maneira jurídica, definir sua situação de acordo com a linguagem jurídica ese comprometer com os procedimentos eas formalidades próprias do métier. Para participar do sistema legal é preciso usar seu sistema referencial para dar sentido às suas demandas.

A partir das teorias deTeubner eLuhmann, daforma especial como concebem a interação dos subsistemas sociais eseus códigos - o que poderíamos chamar de fricções subsistêmicas - , podemos chegar à concepção deque não éapenasa realidadesocial deatores que produzo direito, maso inverso também procede: 0 direito cria realidadesocial, no sentido dequeo código lícito/ ilícito enseja queos atores sociais reordenem suas ações eexpectativas conforme a lógica jurídica subjacente às interações. A teoria sistêmica, portanto, permite a compreensão de processos coletivos, empiricamente constatáveis, em queo centro daação não estálocal izado em forças macro ou microssociológicas, mas no código sistêmico do direito. 
Conclusão

D o nosso ponto de vista, o foco principal das vulnerabilidades episte mológicas da Teoria Sistêmica do D ireito (TSD ), para usar uma das expressões dessa própria perspectiva teórica, é a "acoplagem estrutural" entre a epistemologia assumidamente positivista ("os sistemas existem") de Luhmann, depois acrescida do conceito biológico da autopoiesis, e uma teoria historicista e subjetivista (com sujeitos), desenvolvida por Teubner. Como destacamos, a unidade básica para a compreensão dos sistemas sociais, de acordo com Luhmann, não são os suje itos e suas situações, mas suas comunicações. Segundo esse autor, sujeitos, por exemplo indivíduos, têm interpretações diversificadas e personal izadas das situações, de tal maneira que é impossível subsumi-las em qual quer padrão que permita a compreensão de al go como uma ordem ou um sistema social. D aí que esse padrão sistêmico deva ser procurado na integridade das comunicações que os indi víduos realizam entre si, estas, sim, necessariamente padronizadas para a eficácia das interações. Teubner, embora pretenda assumir esse modelo sistêmico luhmanniano, insere um corpo estranho a essa teoria, que é a idéia de um desenvolvimento histórico ("progressivo") do subsistema do direito empreendido por "sujeitos": classes sociais, corporações de juristas, movimentos sociais etc., o que o autor chama de influência das variáveis "externas". Isso está explícito no diagnóstico sobreo processo dejuridificação das sociedades européias ocidentais, no qual o autor, sem um exame mais acurado dos conceitos relacionados ao tema ${ }^{8}$, identifica os regimes de Welfare State, ou "Estado social", como momentos históricos deinflexão no processo de evolução autopoiética do direito.

O pressuposto teórico da "comunicação" como unidadebásica do sistema social, conforme Luhmann, também merecealguma observação. C omo propõe o autor, a comunicação é resultado da interação de D ois: na natureza, interação de dois indivíduos de uma mesma espécie; nas sociedades humanas, interação de dois sujeitos (atores sociais, por exemplo grupos ou indivíduos). A interação, mediada pela comunicação, é, portanto, resultado da existência de dois seres integrais e independentes. Contra esse pressuposto podemosargumentar queas noções de "D ois" ede "U m", ou seja, a distinção matemática entre um e dois elementos é criação recursiva (cíclica, diria Teubner) da linguagem matemática. No universo social (dos sistemas sociais), a distinção entre as configurações do D ois e do U m é também uma distinção sociolingüística.
8. Teubner assume a existênciadossistemasde Weffarestate como seindicassem uma realidade incontroversa. N averdade, o conceito apresenta inúmerasformulações teóricas que modificam sensivelmente o escopo daação e da compreensão das distintas experiências políticas, sociais eeconômicas abrigadas sob o rótulo de "Welfare State". A esserespeito, ver M ello (1995). 
Em seu magistral estudo sobre a organização política dos índios sulamericanos, Pierre C lastres (1988) oferece um exemplo de muita sensibilidade a respeito de como as concepções do U m e dos múltiplos não se constituem independentementedalinguagem do mundo social epolítico. Entre osíndios $G$ uarani, queeleanalisa detidamente, na reflexão quefazem sobre a infelicidade da condição humana e sobrea perda irreparável da "Terra sem mal", corrompida pelos colonizadores, eles afirmam que o U m éa fonte da infelicidade e o lugar do nascimento do mal. A procura do Bem, na perspectiva dos Guarani, eo que eles consideravam como 0 antagônico ao U m, era o não-U m. Pierre C lastres acredita que por trás dessa equação aparentemente metafísica que iguala o M al ao U m estaria outra equação, "mais secreta e de ordem política", que afirmaria que o U m éo Estado (cf. I dem, pp. 150-151). M as isso já seria um assunto de outra natureza.

0 próprio H umberto M aturana (2001), que tanto serviu de inspiração a Luhmann eao próprio Teubner, refaz, em trabal hos mais recentes sobreos fenômenos associados à cognição humana, o percurso da reflexão sobre a natureza do conhecimento tomando por base alinguagem, como constitutiva de todo o processo cognitivo. A linguagem, afirma, constitui não apenas 0 (objeto) observado, mas também o observador. $E$ afirma: "O resultado desta constituição da linguagem é que nós, seres humanos, existimos como observadores na linguagem, e quaisquer distinções que façamos são operações na linguagem, em conformidade com circunstâncias que surgiram em nós na linguagem" (M aturana, 2001, p. 131).

E numa surpreendenteaproximação à crítica fenomenológicade Edmund H usserl (1986) e Alfred Schutz (1977) ao empirismo, em posição muito distinta, portanto, do positivismo científico, M aturana afirma:

Ao assumirmos quea ciência, como domínio cognitivo constituído através da aplicação do critério de validação das explicaçõescientíficas, não lida com a verdade ou a realidade num sentido transcendente, mas apenas com a explicação da experiência humana no domínio das experiências humanas, muitas questões desaparecem ou perdem inteiramente seu caráter, enovas compreensões são possíveis(2001, p. 159).

Do nosso ponto de vista, a análise sistêmica de Luhmann e Teubner representa uma contribuição importante e original ao acervo teórico da sociologia do direito. Como procuramos demonstrar, ela problematiza a natureza dos vínculos postulados pela teoria sociológica tradicional entre a organização social e a organização do direito, e desfaz, com muita proprie- 
dade, a hipótese clássica dessas teorias a respeito dos vínculos mecânicos entre os interesses materiais e políticos de grupos e classes sociais e a constituição do sistema jurídico. Em seu lugar, a teoria sistêmica propõe um sofisticado modelo que consegue, com rara competência, identificar movimentos especiais resultantes das "friç̧ões" entre os subsistemas sociais: político, econômico e jurídico. A idéia da autonomia autopoiética do direito, despida de seus elementos mais biológicos, identifica um processo totalmente distinto daqueles observados eanal isados exaustivamente pela sociologia tradicional, equeenfatizam a influência das variáveis macrossociológicas na constituição do direito. Em vez disso, a teoria sistêmica afirma uma dupla via na interação desses elementos, de forma que também o direito, isto é, o sistema jurídico stricto sensu, produz "realidade social".

As possibilidades de aplicação da teoria sistêmica podem ser ampliadas, com efeito, se tomarmos seu acervo conceitual não como traduções de verdades essenciais, mas como recursos interpretativos da linguagem dos fenômenosjurídicos e de sua ação, de como esses fenômenos não apenas reagem aos estímulos externos (das realidades), mas, em seus signos próprios, constituem o "real".

Referências Bibliográficas

Boucock, Cary. (2000), In thegrip of freedom : law and M odernityin M axWeber. Toronto, U niversity of Toronto Press.

Clastres, Pierre. (1988), A sociedade contra o Estado. Rio de aneiro, Francisco Alves.

Cotterrell, Roger. (2001), "Isthere a logic of Legal Transplants?". In: N elken , D . \&

FeEst, Johannes (eds.). Adapting legal cultures. 0 xford/Portland, 0 regon, $\mathrm{H}$ art Publishing.

FREUnd, Julien. (1987), Sociologia deM ax Weber. Rio deJaneiro, Forense U niversitária.

Fried M AN, Lawrence M . (1986), "Legal Culture and the Welfare State". In: Teubner,

Gunther (ed.). D ilemmas of law in theW elfare State. Berlim/N ova York, Walter de Gruyter.

H ABERm AS, Jurgen. (1997), D ireito edemocracia. Rio de Janeiro, Tempo Brasileiro, v. I ell. H uSSERL, Edmund. (1986), Ideas relativas a una fenomenología pura y una filosofía fenomenológica. M éxico, Fondo deCultura Económica.

Lem Pert, Richard. (1988), "T heAutonomy of Law: Two VisionsC ompared". In: Teubner, G unther (ed.). Autopoi etic law: a new approach to law and society. Berlim/N ova York, Walter de Gruyter. 
Luhm an n, Niklas. (1983), Sociologia do di reito. Rio deJaneiro, EdiçõesTempo Brasileiro, v. I ell.

. (1986), "Theself-reproduction of law and itslimits". In: T Eubn ER, Gunther (ed.).

Dilemmas of law in theWelfareState Berlim/N ova York, Walter deGruyter. . (1988), "The unity of legal sistem". In: Teubner, Gunther (ed.). Autopoietic law: a new approach to law and society. Berlim/N ova York, Walter de G ruyter. . (1995), Social systems. Stanford, C al ifornia, Stanford U niversity Press. . (2001), Teoría política en el Estado de bienestar. M adrid, Alianza E ditorial.

M ARTINS, M aurício V. (2001), "É o direito um sistema autopoiético? D iscutindo umaobjeção oriunda do marxismo". I n: M ELlo, M arcelo P. (org.). Justiça esoci edade temaseperspectivas. São Paulo, LTr.

M aturana, H umberto. (2001), Cogni ção, ciência evida cotidiana. Belo H orizonte, Editorada UFM G.

M aturana, H umberto \& V arela, Francisco J. (1980), Autopoiesisand cognition. Boston, Reidel.

M ello, M arcelo P. (1995), “W elfareState: crisedo sistema, crise do paradigma e perspectivas pós-industriais". Archétypon, 4 (10), Rio de Janeiro. (org. ). (2001), Justiça esoci edade: temaseperspectivas São Paulo, LTr.

N elken, D avid. (1988), "Changing paradigms in the sociology of law". In: T eubner, Gunther (ed.). Autopoietic law: a new approach to law and society. Berlim/N ova York, Walter deG ruyter.

N eLKen, D avid \& FEest, Johannes(eds.). (2001), Adapting legal cultures 0 xford/Portland, $\mathrm{O}$ regon, $\mathrm{H}$ art Publishing.

N eves, M arcelo da Costa Pinto. (1994), A constitucionalização simbólica. São Paulo, Editora Acadêmica.

N onet, Phillippe\& Selznick, Philip. (2001 [1978]), Law and society in transition. N ew Brunswick, N ew Jersey, Transaction Publishers.

Rотн, Gerhard. (1987), D ieEntwicklung kognitiver Selbstreferencialitat im menschlichen Gehirn. Frankfurt, Suhrkamp.

Schutz, Alfred \& Luckm An, Thomas. (1977). Lasestructurasdel mundo dela vida. Buenos Aires, Amorrortu Editors.

TEUBner, Gunther. (1986), D ilemmas of law in theWelfareState. Berlim/N ovaYork, Walter deG ruyter.

(ed.). (1988), Autopoi etic law: a new approach to law and society. Berlim/N ova York, Walter deG ruyter. . (1989), 0 direito como sistema autopoiético. Lisboa, Fundação CalousteG ulbenkian. . (1996), D roit et réflexi vité: I'auto-référenceen droit et dansl'organisation. Belgique, Bruyland. 
TRUBeCK, D avid. (1972), “M ax W eber on law and the rise of capitalism”. W iscosin Law Review, 3: 720-753.

W ATSO N , A. (1974), Legal transplants: an approach to comparativelaw. Edimburg, Scottish Academic Press.

W eber, M ax. (1991), E conomia esociedade. Brasília, Editora U nB, v. I. . (1999), Economia esociedade, Braślia, Editora UnB, v. II.

\section{Resumo}

A perspectiva sistêmica na sociologia do direito: Luhmann e Teubner

Este artigo se propõe a analisar de forma crítica as contribuições de N iklas L uhmann e Gunther Teubner para o desenvolvimento da Teoria Sistêmica do D ireito (TSD ). Sua hipótese principal éa dequeos autores analisados convergem para uma crítica comum às teses fundamentais das teorias sociológicas clássicas que afirmam que o direito é um epifenômeno das relações sociais dos diversos agentes e seus interesses: indivíduos, classes, corporações, partido etc. A Teoria Sistêmica, ao contrário, afirma que o direito pode ser anal isado como um subsistema social que, a partir da operação de um código próprio, imprimeum sentido eum conteúdo às comunicações dos agentes da ação, detal maneira quenão apenas as relações sociaisentre os agentes criam o direito, mastambém o direito cria realidades orientadoras das ações dosagentes.

Palavras-chave: D ireito; Teoria sociológica; Análisesistêmica; Subjetivismo; H istoricismo; Autopoiess.

\section{Abstract}

A systems approach to the sociology of law: Luhmann and Teubner

Thisarticleproposesa critical analysis of thecontributions of $\mathrm{N}$ iklas Luhmann and $\mathrm{G}$ unther Teubner to the development of the SystemsT heory of Law (STL). Its main hypothesisis that the authors in question converge towards a shared critique of the basic theses of classical sociological theories, which assert that law is an epiphenomenon of the social relations of a variety of agentsand their distinct interests: individuals, classes, corporations, parties, and so on. In contrast, SystemsT heory claimsthat law can beanalyzed as a social subsystem which, based on theoperation of its own code, imprints a meaning and content to the communications of the action's agents. Thisnot only means that law is created by social relations between agents, but that law also creates realities that guidetheactions of agents.

Keywords: Law; Sociological theory; Systemsanalysis; Subjectivism; H istoricism; A utopoiesis.
Recebido em 6/8/2004 e aprovado em 23/10/ 2004.

$M$ arcelo Pereira de $\mathrm{Me}$ Ilo édoutor em Ciência Política (luperj), profes sor adjunto deSociologia da Universidade Federal Fluminense (UFF) edo Programa de Sociologia e Direito (PPGSD/UFF). E mail:mpmello@unisys. com.br. 